Review

\title{
Identification and Selection of Alternative Scenarios in LCA Studies of Integrated Waste Management Systems: A Review of Main Issues and Perspectives
}

\author{
Valentino Tascione * and Andrea Raggi \\ Department of Economic Studies, “G. d'Annunzio” University, Viale Pindaro, 42, Pescara, Italy; \\ E-Mail: a.raggi@unich.it \\ * Author to whom correspondence should be addressed; E-Mail: v.tascione@unich.it; \\ Tel.: +39-085-453-7562; Fax: +39-085-453-7565.
}

Received: 2 August 2012; in revised form: 22 August 2012 / Accepted: 12 September 2012 /

Published: 27 September 2012

\begin{abstract}
Life Cycle Assessment (LCA) is a decision support tool that can be used to assess the environmental performance of an integrated waste management system or to identify the system with the best performance through a comparative analysis of different scenarios. The results of the analysis depend primarily on how the scenarios to be compared are defined, that is on which waste fractions are assumed to be sent to certain treatments/destinations and in what amounts. This paper reviews LCAs of integrated waste management systems with the aim of exploring how the scenarios to be compared are defined in the preliminary phase of an LCA. This critical review highlighted that various criteria, more or less subjective, are generally used for the definition of scenarios. Furthermore, the number of scenarios identified and compared is generally limited; this may entail that only the best option among a limited set of possibilities can be selected, instead of identifying the best of all possible combinations. As a result, the advisability of identifying an integrated life cycle-based methodological approach that allows finding the most environmentally sound scenario among all of those that are theoretically possible is stressed.
\end{abstract}

Keywords: life cycle assessment; integrated waste management system; scenario identification; linear programming 


\section{Introduction}

An objective of European Union (EU) environmental policies is to minimize waste production through better use of resources and more sustainable consumption patterns $[1,2]$. The approach of the EU to integrated waste management is based on the following waste management hierarchy: prevention, preparing for re-use, recycling, other recovery (e.g., energy recovery), and disposal [2]. However, "the waste hierarchy should not be seen as a hard-and-fast rule, particularly since different waste treatment methods can have different environmental impact" [1]. Furthermore, "in order to secure a higher level of environmental protection, the proposal is to modernize the existing legal framework-i.e., to introduce life cycle analysis in policymaking,..." [1]. All phases in a resource's life cycle need to be taken into account, as there can be trade-offs between different phases and measures adopted to reduce environmental impact in one phase can increase the impact in another. Clearly, environmental policy needs to ensure that negative environmental impact is minimized throughout the entire life cycle of resources.

The concept of Life Cycle Thinking is appropriate for this purpose because it is based on a holistic and systematic approach and covers all phases of the life cycle from cradle to grave [3]. Therefore, Life Cycle Thinking and life cycle-based approaches have become very important in the EU sustainability policies.

According to ISO 14040:2006 [4], Life Cycle Assessment (LCA) methodology is applied to assess the potential environmental impacts and resources used throughout a product's life cycle, i.e., from raw material acquisition to waste management. LCA can provide qualitative and quantitative information on energy and resource consumption and production, as well as emissions concerning a given waste management system. LCA can also consider the environmental benefits (related to certain options such as recycling) [5]. Therefore, the LCA tool can be used in policy and decision making to compare various potential management strategies in different districts or regions. In the planning phase, we can build scenarios assuming the rate of each waste fraction that will be conveyed to each of the various treatment/disposal options available.

The term "scenario" is typically used to refer to the "the setting of frame conditions or a description of the system to be modeled" [6]. All of the definitions in the literature include three basic elements: the description of alternative future situations, the pathway from the present to the future and most importantly, the inclusion of uncertainty about the future [6].

According to Börjeson et al. [7], scenarios are developed in a process consisting of three phases: (i) the generation of ideas and data collection; (ii) the integration phase, through which elements are combined into sets; and (iii) checking the consistency of the scenarios. Each phase is developed using specific techniques. Briefly, generating techniques aim to generate a collection of ideas, knowledge and views regarding an aspect of the future (examples of such techniques are workshops, panels and surveys); integrating techniques integrate parts into wholes and are often based on mathematical models; and consistency techniques have as their main advantage the assurance of consistency between or within scenarios.

Regardless of the specific field of LCA, three different categories of scenarios can generally be distinguished [7]: predictive, explorative and normative, which in turn can be divided into other subcategories (as summarized in Table 1). 
More specifically, in the LCA framework, the SETAC-Europe LCA Working Group has defined a scenario as "a description of a possible future situation relevant for specific LCA applications, based on specific assumptions about the future, and (when relevant) also including the presentation of the development from the present to the future" [6].

Table 1. Classification of scenarios according to Börjeson et al. (2006) [7].

\begin{tabular}{|c|c|c|}
\hline \multirow{3}{*}{ Scenarios } & Predictive What will happen? & $\begin{array}{l}\text { Forecast } \\
\text { What will happen, on the condition that the likely } \\
\text { development unfolds? } \\
\text { What-if } \\
\text { What will happen, on the condition of some specified events? }\end{array}$ \\
\hline & Explorative What can happen? & $\begin{array}{l}\text { External } \\
\text { What can happen to the development of external factors? } \\
\text { Strategic } \\
\text { What can happen if we act in a certain way? }\end{array}$ \\
\hline & $\begin{array}{l}\text { Normative How can a specific } \\
\text { target be reached? }\end{array}$ & $\begin{array}{l}\text { Preserving } \\
\text { How can the target be reached, by adjustments to current } \\
\text { situation? } \\
\text { Transforming } \\
\text { How can the target be reached, when the prevailing structure } \\
\text { blocks necessary changes? }\end{array}$ \\
\hline
\end{tabular}

The structure of the scenarios is defined in the first phase of an LCA-the goal and scope definition-but it affects all the other phases of the study. The framing conditions of the defined scenarios give the framework for modeling (which is done in the LCI and LCIA) and the models, in turn, have to follow these conditions [6].

As analysed by Höjer et al. [8], we can identify which of the scenario categories in Table 1 are best suited to the LCA tool considering the background and the foreground system (which are defined as the parts of the LCA model that include "processes on which measures may be taken as a result of decisions based on the LCA study" and "processes which are not under the direct influence of the decision maker", respectively [5]) and an attributional or consequential LCA (an attributional LCA is a model that describes the environmentally relevant physical flows between the system under study and the environment and is a sort of picture of the actual system; in contrast, a consequential model attempts to answer the question of what happens if, so its aim is to identify changes in the environmentally relevant physical flows when there are consequences following possible decisions [9]).

Indeed, forecasts can be used to assess the environmental aspects of all decisions in the background system, but only in its most important part. What-if scenarios are rarely used to describe background systems because of the limited knowledge of the technological subsystem and the causal relationships involved. This type of scenario investigates how certain specific events can change the present situation if they occur. Changes can be internal or external to the system. Essentially, a what-if scenario for a foreground system coincides with a comparative LCA. In contrast, a strategic scenario can be seen as a comparative LCA that includes external scenarios for the background system, and this 
type of scenario can be used for assessing different options for the foreground system under the influence of different external scenarios. A preserving scenario is used to identify a foreground system that meets a specified requirement. In this case, options should be limited to decisions regarding the foreground system, as are options that can influence decision makers [8].

External scenarios are widely used in LCA related to waste management systems. For example, when energy from fuel is replaced by energy recovered from waste incineration. In this case, there will be changes in the fuel system.

Finally, transformative scenarios are not usually involved in LCA because they are used when great changes are needed over a long term. For this reason, there is a problem related to the availability of necessary data for an LCA [8].

Moreover, the following two basic approaches have been proposed in the specific context of LCA scenarios by SETAC-Europe LCA Working Group "Scenario Development for LCA": a what-if scenario and a cornerstone scenario [6].

According to the Authors [6], the most used approach is the what-if scenario. It is used for studies in which researchers can set defined hypotheses on the basis of existing data to compare two or more scenarios. These are often studies that estimate how specific changes may affect environmental impacts within the present system. The result is a quantitative comparison of selected options. This is an approach used in the case of short- or medium-term decision-making situations. This definition reflects the one given for what-if scenarios in the previous classification [7]. However, the SETAC-Europe Working Group focuses on how changes affect specifically environmental impacts. The cornerstone approach does not necessarily give a quantitative assessment. Options are chosen that may be very different from each other and serve as a "cornerstone" of the studied field.

The results of a cornerstone approach are often the basis for further research, where scenarios can be constructed with a what-if approach [6]. According to Pesonen et al. [6], the cornerstone approach is more appropriate for strategic planning and research for the planning of public policies.

In this paper we have carried out a critical review with the aim of providing an overview of how the identification of scenarios in LCA for integrated waste management systems is generally performed. Thus, we will outline the criteria used to identify the scenarios of waste management systems under the LCA and discuss the limitations, strengths and potential improvements. Finally, we will present some preliminary concluding remarks.

\section{Critical Review}

\subsection{Materials and Methods}

We limited the critical review to LCA case-studies analysing various scenarios of integrated waste management systems. The literature search we carried out was based on the following strategy. We searched electronic bibliographic databases, such as Scopus, Caspur Virtual Library (an Italian inter-university database search engine), SBN OPAC (Catalogue of the Italian National Library Service), Wiley InterScience, Google, Google Scholar, ProQuest. The keywords used were: "life cycle assessment", "LCA", "waste management system", "WMS", "municipal solid waste", "MSW", 
"waste", "integrated waste management system", in many combinations. The time period considered was 1999 to 2011. Moreover we browsed the contents of a few LCA-specific journals, including International Journal of Life Cycle Assessment, Journal of Industrial Ecology, Progress of Industrial Ecology, Journal of Cleaner Production, etc.

After a screening process based on the titles and abstracts of the papers found, we took into account only those case studies that explicitly referred to the LCA methodology, to an integrated waste management system and to various scenarios involving different treatment options or different percentages of recycling, thus excluding those case studies assessing individual treatment options.

For example: by searching for "Life Cycle Assessment" AND "municipal solid waste" in Scopus database 224 results were found for the period 1999-2011; however, after the screening process only 4 of them were selected to be reviewed. We further extended the amount of papers to be reviewed through a "snowballing" process, by examining the reference lists of the papers selected to find out which relevant articles those papers cite, and then retrieve them.

Eventually twenty-eight case studies were identified. All of these studies are peer-reviewed papers published in international journals, except for two research reports.

The papers identified were critically reviewed trying to make a connection between classifications discussed in the introduction and scenarios adopted in the case studies with a specific focus on highlighting the criteria used to identify integrated waste management scenarios to be evaluated by comparative LCA and trying to classify them according to type. We define a criterion as the parameter, the rule, the principle adopted to define a hypothetic scenario in terms of amount of waste fractions and the type of destinations involved in the integrated management system under study.

\subsection{Results}

The review highlighted the number of scenarios compared and the criteria used for the construction of scenarios in LCAs for integrated waste management systems. The number of scenarios change depending on the goal of the study. In the twenty-eight case studies reviewed, the number of scenarios ranged from a minimum of 3 to a maximum of 24. Seven case studies compare 3 scenarios, while the remaining case studies consider a variable number of scenarios ranging from 8 to 24 .

In the case studies examined, four types of criteria that were most commonly used were identified and classified; all the other criteria not belonging to these types were grouped in a residual category. Moreover, some studies do not state any specific criteria; rather, the scenarios are presented without explaining their definition process. Table 2 summarises the case studies with the number of scenarios and the relevant criteria used.

The four main criteria referred to are as follows: (i) regulation, standards and guidelines; (ii) good practices; (iii) focus on a specific option; and (iv) forecasts. Among the criteria that cannot be classified according to the categories previously identified, we find, for example, feasible limits to collection for a particular context and valuation of separation efficiency. These are shown in Table 2 under the column "other".

Making reference to regulations is the criterion most commonly used in the definition of the investigated scenarios. Indeed, 13 out of 28 studies based part or all of their assumptions to define hypothetic management scenarios on the objectives and constraints fixed by rules and guidelines at 
various levels. This consists of taking as a reference the minimum and maximum thresholds at local, national and European levels with regard to collection and recovery or the maximum amount of waste sent to landfills, such as the targets of the European 2020 Landfill Directive [10], Landfill Directive 1999/31/EC [11,12] and Packaging Directive 2004/12/EC [12]. Moreover, this category includes criteria related to national recycling targets, such as those set by the Italian legislation for 2003 [13], the 2015 objective set by the government of Kawasaki [14], the national criterion of Thailand [15], the target set by Italian Legislative Decree 152/06 [16]. In the two studies of Rigamonti et al. [17,18] the rate of source separate collection involved is referred to the target for Italy in 2007 and the mid-term regional targets in Italy, respectively. The minimum level of recovery under national regulations - such as the Spanish National Waste Plan for the year 2015 [19] and the percentage of separated collection which is the minimum level required by the Italian legislation [20] —are also used. In one case study, the use of standards and guidelines is just mentioned without, however, going into further details [21].

The good practice criterion consists of taking an already existing and widespread waste management system as a reference, such as different collection models implemented in Spain at a national level [19], the level of source-separated collection that has been reached in the year of the study in some provinces in the North of Italy [18], and the options being considered by several Italian municipalities to recover energy from waste in the year of the study [13].

Another method commonly found in the studies we reviewed consists of focusing on a specific option, such as a given waste treatment process or type of waste. This method can mean placing emphasis on the recovery of a specific waste fraction or on the quality of the materials recovered [22,23], though it can also assume the intensive use of a particular process, such as recycling, composting, incineration or biochemical mechanical treatment (BMT) [11,12,24]. The case study of Torino District [25], in Italy, offers four scenarios where recycling is emphasised. However, how these rates were set was not specified.

The forecast criterion is very specific to the context and to the purpose of the study. Pires et al. [11], in one of the alternatives studied, refer to "the predicted change that will take place" in the waste management system under study.

In the case of a project involving new plants (for example, an incineration or material recovery plant), a forecast can be a projection of current project data to the time when the new plant will start to operate [26]; or it can be an estimation of the level of collection that could be achieved within a specific time [18].

As noted above, we identified a number of adopted criteria that do not occur in more than one case study. These criteria are as follows (related studies in brackets):

- $\quad$ The maximum feasible level of waste separation [27];

- The maximum capacity of treatment plants and landfills [15];

- The separation efficiency estimated with a method that takes into account the amount of a fraction generated and the separated amount of that fraction [28];

- The percentage of recycling collection starting from a fixed base rate and adding a fixed arbitrary rate for each subsequent scenario up to the maximum feasible rate [20]; 
- The choice of technologies that meet the objectives of environmental policies and that are suitable for the context, such as the composting process, which is considered a low-technology option and, thus, suitable for developing countries [29];

- A set of non-detailed criteria, such as waste generation, technological possibilities and the potential market for the recovery of recyclable materials [21].

Moreover, as shown in Table 2, we identified a further category of case studies ("Non specified criteria") including those in which the criteria used to define all or some scenarios are not specified. In describing the study and the scenarios for evaluation and comparison, the criteria used to define the assumed scenarios are not clear, specifically with respect to the choice of certain waste management options as regards both the percentages of waste involved and the technologies and processes chosen [19,21-24,28-37].

Table 2. Number of scenarios and relevant criteria used in the reviewed case studies.

\begin{tabular}{|c|c|c|c|c|c|c|c|}
\hline \multirow[b]{2}{*}{ Case Studies } & \multirow[b]{2}{*}{$\begin{array}{c}\text { Number of } \\
\text { Scenarios }\end{array}$} & \multicolumn{6}{|c|}{ Criteria } \\
\hline & & $\begin{array}{c}\text { Regulations, } \\
\text { standards and } \\
\text { guidelines }\end{array}$ & $\begin{array}{c}\text { Good } \\
\text { practices }\end{array}$ & $\begin{array}{c}\text { Focus on a } \\
\text { specific option }\end{array}$ & Forecasts & $\begin{array}{c}\text { Not specified } \\
\text { criteria }\end{array}$ & $\begin{array}{l}\text { Other } \\
\text { criteria }\end{array}$ \\
\hline Hassan et al. 1999 (Malaysia) [33] & 3 & & & & & $\sqrt{ }$ & \\
\hline Barlaz et al. 2003 (USA) [30] & 3 & & & & & $\sqrt{ }$ & \\
\hline Beigl, Salhofer 2004 (Spain) [31] & 3 & & & & & $\sqrt{ }$ & \\
\hline Muñoz et al. 2004 (Spain) [21] & 7 & $\sqrt{ }$ & & & & & $\sqrt{ }$ \\
\hline Consonni et al. 2005 (Italy) [13] & 4 & $\sqrt{ }$ & & & & & \\
\hline Eriksson et al. 2005 (Sweden) [27] & 4 & & & & & & $\sqrt{ }$ \\
\hline Bovea, Powell 2006 (Spain) [23] & 5 & $\sqrt{ }$ & & $\sqrt{ }$ & & $\sqrt{ }$ & \\
\hline Hong et al. 2006 (China) [24] & 5 & & & & & $\sqrt{ }$ & $\sqrt{ }$ \\
\hline Buttol et al. 2007 (Italy) [26] & 3 & & & & $\sqrt{ }$ & & \\
\hline Emery et al. 2007 (UK) [10] & 4 & $\sqrt{ }$ & & & & & \\
\hline Koneczny et al. 2007 (Europe) [12] & 7 & $\sqrt{ }$ & & $\sqrt{ }$ & & & \\
\hline Salhofer et al. 2007 (Austria) [35] & 8 & & & & & $\sqrt{ }$ & \\
\hline Blengini et al. 2008 (Italy) [25] & 4 & & & $\sqrt{ }$ & & & \\
\hline Conteras et al. 2008 (USA) [32] & 3 & & & & & $\sqrt{ }$ & \\
\hline Liamsanguan, Gheewala 2008 (Thailand) [15] & 4 & $\sqrt{ }$ & & & & & $\sqrt{ }$ \\
\hline Rigamonti et al. 2008 (Italy) [17] & 3 & $\sqrt{ }$ & $\sqrt{ }$ & & $\sqrt{ }$ & & \\
\hline Banar et al. 2009 (Turkey) [22] & 5 & & & $\sqrt{ }$ & & $\sqrt{ }$ & \\
\hline Batool, Chuadhry 2009 (Pakistan) [29] & 6 & & & & & $\sqrt{ }$ & $\sqrt{ }$ \\
\hline De Feo, Malvano 2009 (Italy) [20] & 12 & $\sqrt{ }$ & $\sqrt{ }$ & & & & $\sqrt{ }$ \\
\hline Luoranen et al. 2009 (Lithuania) [28] & 6 & & & & & $\sqrt{ }$ & $\sqrt{ }$ \\
\hline Rigamonti et al. 2009 (Italy) [18] & 2 & $\sqrt{ }$ & $\sqrt{ }$ & & & & \\
\hline Zhao et al. 2009 (China) [36] & 7 & & & & & $\sqrt{ }$ & \\
\hline Bovea et al. 2010(Spain) [19] & 24 & $\sqrt{ }$ & $\sqrt{ }$ & & & $\sqrt{ }$ & $\sqrt{ }$ \\
\hline Geng et al. 2010 (China) [14] & 5 & $\sqrt{ }$ & & & & & \\
\hline Pires et al. 2011(Portugal) [11] & 18 & $\sqrt{ }$ & & $\sqrt{ }$ & $\sqrt{ }$ & & \\
\hline Koci et al. 2011 (Czech Republic) [34] & 7 & & & & & $\sqrt{ }$ & \\
\hline Tunesi 2011 (UK) [37] & 9 & & & & & $\sqrt{ }$ & \\
\hline Giugliano et al. 2011 (Italy) [16] & 4 & $\sqrt{ }$ & & & & & \\
\hline
\end{tabular}




\subsection{Discussion}

The studies analysed were mainly carried out using what-if scenarios of the predictive category (Table 1). The nature of the scenarios in these studies meets the what-if scenario definition given by Höjer et al. [8] and Pesonen et al. [6]. According to these authors, what-if scenarios are those that investigate what will happen in the near future given certain events or decisions of great importance for future developments. Furthermore, a what-if scenario, being comparative (compared to baseline scenario or "business as usual"), for the foreground system coincides with a comparative LCA (this is the case for the kind of studies that compare scenarios of integrated waste management systems). Finally, to define what-if scenarios to be compared, researchers usually set hypotheses on the basis of existing data and information. This leads to the identification of limited sets of scenarios, which are based on various criteria, more or less subjective, that we classified in 6 categories (Table 2).

The choice of the criterion or method for defining scenarios may depend on the objective of the study. Therefore, the authors decide what they consider is the most appropriate criterion for scenario definition to achieve that goal. In most cases the adopted criterion turned out to be adequate. For example, in cases where the criterion chosen belongs to what we have classified as "regulations, standards and guidelines", we can infer that the objective of the study is to assess whether, a more environmentally-sound system can be obtained by adopting given environmental policies. For example, in the case of [15] the study focuses on greenhouse gas (GHG) emissions and how these emissions can be reduced by considering several alternative waste management systems. The results of the study are intended to support decision-making processes regarding waste management policies and environmental policies. This is because in many countries-including Thailand, where the study was conducted - climate change and the reduction of GHG emissions are considered as important factors that may lead to changes in waste management systems [15]. So, in this case, the choice of criteria related to "regulations, standards and guidelines" results to be consistent.

In the case of [26] the objective of the study is to highlight the benefits of using LCA to develop new plans of waste management. In this case, the purpose is generic, but scenarios are defined by assuming an increase in the production of waste and, therefore, the need of new incineration plants. We can infer that authors want to highlight how LCA can be helpful if policy makers want to assess new investments. So the criterion "forecasts" is consistent.

The case study in [19] describes quite clearly on which elements the authors based their scenario definition. For example, some elements can be classified as "regulations, standards and directives", whilst others as "good practices". The use of multiple criteria simultaneously may be a way to define more precisely scenarios to be compared rather than the use of a single criterion.

However, even though in the three previous examples the definition of scenarios occurs in a valid, reasonable and consistent manner, we can highlight some limitations concerning possible arbitrariness in the definition, for example, of recycling rates and the processes involved in the system. Moreover, the number of scenarios compared is always limited due to the lack of time and resources often available for studies.

So, however accurate and broad the scenario definition may be, there is a possibility that decision makers ignore theoretically and technically possible scenarios that are environmentally preferable. Therefore, it is appropriate to develop a methodology that integrates LCA and identifies the most 
environmentally-sound scenario among all of those possible, according to a given set of constraints related a specific context under evaluation. This tool could be a useful support for decision making.

A promising answer to this problem can be found in linear programming models (LP). Instead of defining a priori a limited set of scenarios to be compared, the best eco-efficiency combination can be determined as a solution of a linear programming problem from within all those theoretically and technically possible alternatives. As discussed by Ekvall et al. [38], LP models are linear models that account for boundary conditions. According to Solano [39], LP models may be applicable when there are not many combinations of waste flow paths present. However, when considering a large number of unit processes with numerous combinations of waste flow paths, the mathematical equations for maintaining mass balance become nonlinear.

LP optimisation models for waste management systems can be integrated into an LCA. The ORWARE and MIMES/waste models are examples of LP models that integrate the life-cycle perspective and are also tools for LCA [40]. However, according to Ekvall et al. [38], an LP model is not a very precise representation of a real system. Non-linear programming is useful for evaluating more complex non-linear relationships. Though, a more complex system requires more data, and high quality data for an LP model can be difficult to obtain. For example, it is difficult to estimate the maximum collection rate that can be achieved through bring systems [38].

Papers published by Solano et al. [41,42] present a Life-Cycle-Based Model for a Waste Management System. This linear programming model allows decision makers to identify alternative integrated strategies that meet cost, energy and environmental emission objectives. A life-cycle approach is used to compute energy consumption and emissions. A life-cycle inventory (LCI) of a total of thirty-two environmental parameters is made for all unit processes. Furthermore, the model is flexible to allow the representation of site-specific issues. A weakness of this model is that its optimisation process must be carried out for one specific impact category at a time.

Mercuri and Raggi [43] proposed a model that is easier to perform than the model proposed by Solano $[41,42]$, but it has the same limitation. However, those models could be improved and extended by simultaneously considering various impacts and by including also economic issues.

\section{Conclusions}

The results of this critical review showed that scenario definition in LCA studies as applied to Integrated Waste Management Systems takes place according to various criteria, which we classified according to common characteristics. Four criteria are most commonly used to define scenarios: (i) standards and guidelines; (ii) good practices; (iii) focus on a specific waste management option; and (iv) forecasts. Besides these criteria, others were found that cannot be classified according to the categories previously identified. Additionally, in some studies, the criteria followed are not clear.

Furthermore, we found that all of the reviewed studies consider only a limited number of scenarios (from 2 to 24). This might be a limitation: indeed, however accurate and broad the scenario definition may be, the scenario actually generating the lowest environmental impacts might just not be included among the alternatives proposed and analysed in a specific study.

The results of this review emphasised the need to develop a methodology to assist with choosing the best scenarios for integrated waste management. This methodology, which can be integrated into LCA 
according to a life cycle view, could be found in the linear programming field. By means of such an approach, instead of defining a limited set of a-priori scenarios to be compared, the best environmentally performing combination could be determined as a solution of a linear programming problem from within all those theoretically and technically possible alternatives.

Solano et al. [41,42] and Mercuri and Raggi [43] have suggested two models based on linear programming. The former is a life-cycle-based model and is more complex than the latter, but both present a limitation in that they consider a single impact category at a time.

An ideal methodology should enable users to manage all impacts simultaneously, which can be achieved by improving the existing linear programming models, or using other types of mathematical tools.

Future research should continue on this path in an attempt to determine whether such an instrument can be identified.

\section{Conflict of Interest}

The authors declare no conflict of interest.

\section{References}

1. European Commission. Communication from the Commission to the Council, the European Parliament, the European Economic and Social Committee and the Committee of the RegionsTaking Sustainable Use of Resources Forward: A Thematic Strategy on the Prevention and Recycling of Waste; COM(2005) 666 Final; Commission of the European Community: Brussels, Belgium, 21 December 2005.

2. European Commission. EC Directive 2008/98/EC of the European Parliament and of the Council of 19 November 2008 on waste and repealing certain Directives. Official Journal of the European Union, L 312/3; European Commission: Brussels, Belgium, 22 November 2008.

3. Franke, M.; McDougall, F. Integrated Waste Management: LCA and Its Practical Use. In Proceedings of the First International Conference on Waste Minimization and Recycling, Buenos Aires, Argentina, 3-4 May 1999; pp. 3-4.

4. ISO 14040. Environmental Management-Life Cycle Assessment-Principles and Framework; International Organisation for Standardisation: Geneva, Switzerland, 2006.

5. Baumann, H.; Tillman, A.M. The Hitch Hiker's Guide to LCA; Studentilitteratur: Lund, Sweden, 2004.

6. Pesonen, H.-L.; Ekvall, T.; Fleischer, G.; Huppes, G.; Jahn, C.; Klos, Z.S.; Rebitzer, G.; Sonnemann, G.W.; Tintinelli, A.; Weidema, B.P.; Wenzel, H. Framework for scenario development in LCA. Int. J. Life Cycle Assess. 2000, 5, 21-30.

7. Börjeson, L.; Höjer, M.; Dreborg, K.; Ekvall, T.; Finnveden, G. Scenario types and techniques: Towards a user's guide. Futures 2006, 38, 723-739.

8. Höjer, M.; Ahlroth, S.; Dreborg, K.-H.; Ekvall, T.; Finnveden, G.; Hjelm, O.; Hochschorner, E.; Nilsson, M.; Palm, V. Scenarios in selected tools for environmental systems analysis. J. Clean. Prod. 2008, 16, 1958-1970. 
9. Finnveden, G.; Hauschild, M.Z.; Ekvall, T.; Guinée, J.; Heijungs, R.; Hellweg, S.; Koehler, A.; Pennington, D.; Suh, S. Recent developments in life cycle assessment. J. Environ. Manag. 2009, 91, 1-21.

10. Emery, A.; Davies, A.; Griffiths, A.; Williams, K. Environmental and economic modelling: A case study of municipal solid waste management scenarios in Wales. Resour. Conserv. Recycl. 2007, 49, 244-263.

11. Pires, A.; Chang, N.-B.; Martinho, G. Reliability-based life cycle assessment for future solid waste management alternatives in Portugal. Int. J. Life Cycle Assess. 2011, 16, 316-337.

12. Koneczny, K.; Dragusanu, V.; Bersani, R.; Pennington, D.W. Environmental Assessment of Municipal Waste Management Scenarios: Part I-Data Collection and Preliminary Assessments for Life Cycle Thinking Pilot Studies; Report; JRC, Office for Official Publications of the EC: Luxembourg, Luxembourg, 2007.

13. Consonni, S.; Giugliano, M.; Grosso, M. Alternative strategies for energy recovery from municipal solid waste. Part A: Mass and energy balances. Waste Manag. 2005, 25, 123-135.

14. Geng, Y.; Tsuyoshi, F.; Chen, X. Evaluation of innovative municipal solid waste management through urban symbiosis: A case study of Kawasaki. J. Clean. Prod. 2010, 18, 993-1000.

15. Liamsanguan, C.; Gheewala, S.H. The holistic impact of integrated solid waste management on greenhouse gas emissions in Phuket. J. Clean. Prod. 2008, 16, 1865-1871.

16. Giugliano, M.; Cernuschi, S.; Grosso, M.; Rigamonti, L. Material and energy recovery in integrated waste management systems: An evaluation based on life cycle assessment. Waste Manag. 2011, 31, 2092-2101.

17. Rigamonti, L.; Grosso, M.; Giugliano, M. Life cycle assessment for optimising the level of separated collection in integrated MSW management systems. Waste Manag. 2008, 29, 934-944.

18. Rigamonti, L.; Grosso, M.; Sunseri, M.C. Influence of assumptions about selection and recycling efficiencies on the LCA of integrated waste management systems. Int. J. Life Cycle Assess. 2009, 14, 411-419.

19. Bovea, M.D.; Ibáñez-Forés, V.; Gallardo, A.; Colomer-Mendoza, F.J. Environmental assessment of alternative municipal solid waste management strategies: A Spanish case study. Waste Manag. 2010, 30, 2383-2395.

20. De Feo, G.; Malvano, C. The use of LCA in selecting the best MSW management system. Waste Manag. 2009, 29, 1901-1915.

21. Muñoz, I.; Rieradevall, J.; Domenech, X.; Milà, L. LCA application to Integrated Waste Management planning in Gipuzkoa (Spain). Int. J. Life Cycle Assess. 2004, 9, 272-280.

22. Banar, M.; Cokaygila, Z.; Ozkana, A. Life cycle assessment of solid waste management options for Eskisehir, Turkey. Waste Manag. 2009, 29, 54-62.

23. Bovea, M.D.; Powell, J.C. Alternative scenarios to meet the demands of sustainable waste management. J. Environ. Manag. 2006, 79, 115-132.

24. Hong, R.J.; Wang, G.F.; Guo, R.Z.; Cheng, X.; Liu, Q.; Zhang, P.J.; Qian, G.R. Life cycle assessment of BMT-based integrated municipal solid waste management: Case study in Pudong, China. Resour. Conserv. Recycl. 2006, 49, 129-146. 
25. Blengini, G.A.; Genon, G.; Fantoni, M. LCA del Sistema Integrato dei RSU nella Provincia di Torino. Analisi Energetico Ambientale con Metodologia LCA ed Analisi Economica dell'Attuazione del Piano Provinciale di Gestione dei Rifiuti alla Luce dei Nuovi Obiettivi di Raccolta Differenziata Introdotti dal D.lgs. 152/06; Report; Politecnico di Torino DITAG e DISPEA: Torino, Italy, 2008.

26. Buttol, P.; Masoni, P.; Bonoli, A.; Goldoni, S.; Belladonna, V.; Cavazzuti, C. LCA of integrated MSW management systems: Case study of the Bologna District. Waste Manag. 2007, 27, 1059-1070.

27. Eriksson, O.; Carlsson, R.M.; Frostell, B.; Björklund, A.; Assefa, G.; Sundqvist, J.-O.; Granath, J.; Baky, A.; Thyselius, L. Municipal solid waste management from a systems perspective. J. Clean. Prod. 2005, 13, 241-252.

28. Luoranen, M.; Soukka, R.; Denafas, G.; Horttanainen, M. Comparison of energy and material recovery of household waste management from the environmental point of view - Case Kaunas, Lithuania. Appl. Therm. Eng. 2009, 29, 938-944.

29. Batool, S.A.; Chuadhry, M.N. The impact of municipal solid waste treatment methods on greenhouse gas emissions in Lahore, Pakistan. Waste Manag. 2009, 29, 63-69.

30. Barlaz, M.A.; Kaplan, P.O.; Ranjithan, S.R.; Rynk, R. Evaluating environmental impacts of solid waste management alternatives. BioCycle 2003, 44, 52-56.

31. Beigl, P.; Salhofer, S. Comparison of ecological effects and costs of communal waste management systems. Resour. Conserv. Recycl. 2004, 41, 83-102.

32. Contreras, F.; Hanaki, K.; Aramaki, T.; Connors, S. Application of analytical hierarchy process to analyze stakeholders preferences for municipal solid waste management plans, Boston, USA. Resour. Conserv. Recycl. 2008, 52, 979-991.

33. Hassan, M.N.; Awang, M.; Chong, T.L.; Zakaria, Z.; Lay, L.B.; Yusoff, N.; Sino, H. The application of an Life Cycle Inventory (LCI) model for solid waste disposal systems in Malaysia. Int. J. Life Cycle Assess. 1999, 4, 188-190.

34. Koci, V.; Trecakova, T. Mixed municipal waste management in the Czech Republic from the point of view of the LCA method. Int. J. Life Cycle Assess. 2011, 16, 113-124.

35. Salhofer, S.; Wassermann, G.; Binner, E. Strategic environmental assessment as an approach to assess waste management systems: Experiences from an Austrian case study. Environ. Modell. Softw. 2007, 22, 610-618.

36. Zhao, W.; van der Voet, E.; Zhang, Y.; Huppes, G. Life cycle assessment of municipal solid waste management with regard to greenhouse gas emissions: Case study of Tianjin, China. Sci. Total Environ. 2009, 407, 1517-1526.

37. Tunesi, S. LCA of local strategies for energy recovery from waste in England, applied to a large municipal flow. Waste Manag. 2011, 31, 561-571.

38. Ekvall, T.; Assefa, G.; Björklund, A.; Eriksson, O.; Finnveden, G. What life-cycle assessment does and does not do in assessments of waste management. Waste Manag. 2007, 27, 989-996.

39. Solano, E. Life cycle assessment of municipal solid waste management alternatives: An integrated optimization model. MS Thesis, Department of Civil Engineering, North Carolina State University: Hillsborough Raleigh, NC, USA, 1996. 
40. Eriksson, O.; Olofsson, M.; Ekvall, T. How model-based systems analysis can be improved for waste management planning. Waste Manag. Res. 2003, 21, 488-500.

41. Solano, E.; Ranjithan, S.R.; Barlaz, M.A.; Brill, E.D. Life-cycle-based solid waste management. I: Model development. J. Environ. Eng. 2002, 128, 981-992.

42. Solano, E.; Dumas, R.D.; Harrison, K.W.; Ranjithan, S.R.; Barlaz, M.A.; Brill, E.D. Life-cycle-based solid waste management. II: Illustrative applications. J. Environ. Eng. 2002, 128, 981-992.

43. Mercuri, L.; Raggi, A. A Proposal for a Mathematical Model to Identify Optimal Scenarios for Waste Management System. In Proceedings of 6th International Conference on EcoBalance, Tsukuba, Japan, 25-27 October 2004; pp. 481-482.

(C) 2012 by the authors; licensee MDPI, Basel, Switzerland. This article is an open access article distributed under the terms and conditions of the Creative Commons Attribution license (http://creativecommons.org/licenses/by/3.0/). 